\title{
Art and Resilience: The Artist's Survival in the Spanish Art Market - Analysis from a Global Survey
}

\author{
Marta Pérez-Ibáñez ${ }^{1, *}$, Isidro López-Aparicio ${ }^{2}$ \\ ${ }^{1}$ School of Communication and Arts, Nebrija University, Spain \\ ${ }^{2}$ Faculty of Fine Arts, University of Granada, Spain
}

Copyright $\odot 2018$ by authors, all rights reserved. Authors agree that this article remains permanently open access under the terms of the Creative Commons Attribution License 4.0 International License

\begin{abstract}
This article aims to diagnose certain characteristics of the resilient personality in the Spanish artists who developed their artistic careers in the years before the economic crisis that began in 2008 and who have suffered the resulting loss in their activity and their economy. Along with sources of positive psychology that analyze resilience as an individual's personal and social ability to effectively overcome situations of crisis, this paper is based on the research developed by the authors in recent years from data provided by more than 1,100 visual and plastic artists in Spain, a wide survey about the economic situation of this sector nowadays and the evolution since the beginning of the economic crisis. It also seeks to determine whether there is a resilient artist profile, which through personal, social and professional tools, has reoriented his career and maintains his artistic activity as the main source of income. The methodology used, both analytic and descriptive, allows determining not only what characteristics of the resilient personality may be detected in this group of artists, but also which tools they use to survive the crisis in the current art market.
\end{abstract}

Keywords Artists, Resilience, Crisis, Economy, Precariousness, Art Market, Positive Psychology

The pessimist complains about the wind; the optimist expects it to change; the realist adjusts the sails

William Arthur Ward

\section{Introduction}

The critical economic situation that the art system and the art market are going through since the beginning of the global crisis in 2008 and the precariousness of the artists' work and their needs to adapt to these new conditions give us a new dimension that must be evaluated. Away from the highlights of the millions of dollars' sales in blue chip galleries and auction houses, away from the glamour of art fairs and museum exhibitions, the largest majority of the artists in the world, have suffered the closure of their reference galleries due to the financial recession, and have therefore lost most of their source of income. Along with the change of business models in many of the new opening galleries, the relationship between artists and the art market is showing signs of a profound evolution, where the whole of the artistic activity of creators in undergoing a deep change of paradigm in order for them to survive, to overcome the crisis and to keep making a living as an artist. They are mostly self-employed workers with a high degree of unemployment, with incomes that are barely around the minimum inter-professional wage, with serious difficulties to meet the usual expenses and with less capacity than the national average to face a mortgage or to look after dependent people, with few years of contribution to the Social Security System and with the consequent insecurity before the future benefits of retirement. In order to adapt their careers to the new circumstances, artists have had to be flexible and adaptable, distinguishing what was and what was not within their control, changing their attitudes and establishing new professional relations (Neenan, 2017 [47]). This problem, far from being local or restricted to countries like Spain, is global and affects artists all over the world. The precariousness of the artists' life in our society, which has been a largely studied issue (Abbing [2]; Bağcıoğlu [5]; Bille, Løyland \& Holm [8]; Bille \& Jensen [9]; Bass, Milosevic \& Eesley [7]; Dekel [14]; Filler, 1986; Gill \& Pratt [21]; Klamer [33]; Lena \& Lindemann [36]; McAndrews [39]; Michael [43]; Robinson \& Montgomery [50]; Steiner \& Schneider [57]; Throsby [58, 59]; Wassall \& Alper [60]), offers now the challenge of finding out which resources, social, professional or psychological, what degree of resilience, are the artists using to confront this difficult situation.

The concept of resilience has been the subject of study for psychology for a long time, but in recent years the number of studies aimed at analyzing this particularity of character in the professional activity of people has grown significantly. Most research on resilience is circumscribed 
to the field of positive psychology ${ }^{1}$, on which Martin Seligman has focused his studies to analyzing in an empirical way the psychological and emotional impulses related to the self-protection and the resistance of the individual to situations of crisis (Seligman, 2005; Seligman, 2006) ${ }^{2}$. The publication of the Handbook of adult resilience notes the individual and psychological component of resilience both in research and in practice, over and above the social or circumstantial component (Reich, Zautra and Hall [48]), to which it is also undoubtedly debtor. This social component has also been extensively studied (Saleebey [51]; Guo and Tsui [24]), combining it with the individual character or personality with a tendency towards resilience. Thus, the combination of certain factors or individual, family or social circumstances would facilitate the construction of mechanisms of defense against adversity, factors such as a good relationship with family members (Richaud [49]), a character conducive to social interaction or the ability to overcome conflict situations (Greene and Greene [23]). We have also taken into account studies such as that of Steiner and Schneider [56] in which they argue that, despite the adversities involved in artistic work, such as low wages and salaries, above-average unemployment, low demand for artistic production and difficulties to contribute enough and guarantee future benefits, however, it produces a high professional and personal satisfaction. Some authors have expressed (Abbing [2]; Adler [3]; Menger [41]; Rengers, 2002; Filer [16]; Galenson [20]) that artists feel psychologically rewarded by considering their activity highly attractive and satisfying. The influence lies on different factors such as the variety of work they perform, high level of personal autonomy in the use of the self-initiative, the opportunity it operate with different skills and constantly update them, the capacity for learning and updating, the low level of routine, the high degree of recognition and social cohesion within the sector, etc. These are circumstances that allow artists, in general, to be more satisfied with their work and professional activity than other workers in different sectors, which supports our thesis that associated with artistic activity, there is a psychological component that allows the creator to positively assimilate his work, even in spite of the difficulties involved. In our study we will see how these

1 Positive psychology as a scientific discipline, circumscribed within the scope of academic psychology and, in a way, opposed to clinical psychology or psychopathology, seems to us the most adequate way to study resilience in artists, since it allows us to deepen those attitudes and individual abilities that help or influence the development of life optimally, counteracting adversity and seeking physical, psychological and social well-being (Seligman, 2011). Considering resilience, the ability to overcome and grow in the face of adversity, as one of the factors that study positive psychology, we wanted to start from the authors who have delimited this concept and its applications in the social and professional sphere as a starting point for our study, which we will review throughout this paper and that will lead us to the final conclusions.

2 One of the sources consulted for our study, A Handbook of Positive Psychology (Snyder and Lopez [56]), often refers to Seligman's studies of resilience as a reference in this field. factors are decisive for deciphering how certain visual and plastic artists in Spain are being able to cope with the present precarious situation, especially in those circumstances in which the artist is supported by the family, social and professional environment in which it develops its activity, a factor that is essential in many occasions. Starting from the research on the economic activity of artists in Spain (Pérez-Ibáñez \& López-Aparicio, 2017), we will extract the results that, on this group in particular, will allow us to identify such attitudes and concretize whether there is indeed a profile of a resilient artist.

Taking into account the definition of the term "resilience", it seemed to us that it suits well the way in which certain artists who, having experienced a very different economic situation in the years prior to $2008^{3}$, the beginning of the current economic crisis which our country suffers, have managed to redirect their artistic activity, whether in terms of production itself, communication channels, strategies to approach the market or the relationships established with the art system. In short, artists who have overcome the obstacle, have rebuilt their career and are managing to continue with their artistic activity as their main source of income, at a time when the sale of works of art in Spain has significantly decreased, many art galleries have closed and, those that are still active or those that have recently opened, recognize that this business model has been altered in a sensitive way. This ability of artists to gain new markets, to make themselves known directly without the intermediary figure of the art dealer, to establish their own communication networks for their artwork and to keep their brand image active are, in our opinion, symptoms of a very significant resilience, an important ability to overcome adversity and to move forward. The latest Eurostat report (Eurostat [15] 60-63) focuses on the fact that, in relation to general employment data in European countries with respect to the crisis that began in 2008, jobs related to cultural activities and industries have shown greater resilience, showing a decline between 2011 and 2012 and a recovery that is also noticeable since then, a recovery that has remained stable so far, even more than the general employment data in Europe. Of course, as we will see in this paper and in the study from which it is derived, not all artists demonstrate such capacities, and we will even find cases in which the towel has been "thrown in" by the difficulty of maintaining the artistic activity at the same level as other profitable professional activities. But the existence of resilient artists has motivated us to study the characteristics of this ability and how our creators develop it. For this, we will review some of the theoretical references on the study of resilience

3 We agree with other sources to put the cutoff point on the beginning of the current economic crisis in 2008, the date of the fall of the financial services firm Lehman Brothers. Among others, Dr. Clare McAndrew in her 2012 study on the Spanish art market (page 11), refers to "two years of market contraction, from 2007 to 2009". Therefore, we assume this reference and put in our analysis the year 2008 as a turning point from which the overall market situation changes drastically in Spain. 
in psychology, like those bay Seligman, Saleebey, Guo, Tsuy, Greene, Barney, Hunter, Menezes, Moran, Bonanno, Hobfol, Kobasa, Maddi, Cicchetti, Cheeseman, Fletcher \& Sarkar and others, Meagan Shand's (2014) study of resilience in art, we will comment on the activity of CERF + in promoting and supporting the resilience of artists and compare it with the situation in Spain.

It is important to emphasize, however, that when we refer to the resilience of Spanish artists we are mentioning mainly the artists who have known the situation prior to the current economic crisis, that is, those artists who have been subdued to that "force that deformed them "and who have come out well and strengthened, understanding that force as the drastic reduction in the economic performance of their artistic activity, and understanding their resilience as the capacity with which they have been able to recover in their professional activity, to look for new channels of work and sale, and continue to maintain such activity, as we have already mentioned, as their main source of income. The young generation of artists "born" professionally during the crisis, a profile that is also the subject of our study as that represents the future of Spanish creators, new strategies, objectives and results, have known the current economic situation in our country and in this sector as they are currently experiencing it. We can say that they have not known a different situation, have not suffered a drastic impairment in their economic activity, and have not seen their galleries closed or lost their place in the art market.

As Shand also points out in his extensive study on artist resilience (2014), certain resources and abilities that allow the artist to overcome critical moments and to maintain themselves over time are assets that the artist acquires with the practice and performance of their activity, and may not be learned or acquired in an immediate way (Barney [6]), even if these assets can be considered inherent to their own character from childhood and existing in the individual from that age (Hunter [29]), or even inherited generationally (Fonagy [18]; Anthony and Cohler [4]), so it is premature for us to attribute such a level of resilience to young artists. In short, their economic situation is developing from the current economic context, adapting to the available circumstances and resources, and taking advantage of the current situation to be able to survive in this activity. We can not, therefore, identify them with that other profile of artist that has survived the crisis thanks to their resilience, and must demonstrate this ability in other areas, and perhaps in other situations. Although, as Montero and Oreja [45] point out, young artists use strategies of promotion and commercial distribution different from established artists, adapted to their incipient relationship with market agents, we will be interested to know, throughout our study, how they develop such activities.

In the performance of their activity, each artist has a series of resources that they control, combine and use to carry out their artistic production throughout their career and to differentiate their value from other artists (Kay [30]). These resources, which may be the artist's own or come from third parties related to him (Grant et al [22]), are combined and related according to the artist's own abilities, skills and attitudes, experience and technical skills, according to the time they have been carrying out this activity, but also to their relations with art market agents. The role played by gallerists and artists in information, communication, relationship with buyers and, ultimately, the satisfaction of the demand for art during the period prior to the crisis of 2008 was studied by Meyer and Even [42], leaving a record of the alternative marketing formulas used by artists as a way to promote their work, and the success that these formulas obtained in the market (Karttunen [31, 32]). At the present time, as we see in this study, the alteration of the results of certain strategies that have been successful in past decades obliges each other to modify in an equivalent way both the resources used and the objectives of their strategies, which implies the need to use resilience mechanics that allow each other to stay afloat and continue to grow.

In the three reports presented so far by Dr. McAndrew [37-39] about the recent evolution of the Spanish art market, we can see not only the decline in the art trade in general in our country, from the beginning of the crisis and in particular between 2012 and 2014, but specifically the decrease in number of registered art galleries ${ }^{4}$. If, as we can see, the primary market in Spain generates $70 \%$ of the total sales of the art market in Spain (McAndrew [38] 27), the economy of the artists must be based, necessarily, on the sales of their works carried out by the galleries, main channel of promotion and distribution of works of art directly coming from the artists. Therefore, the closure of many of them in the years after the beginning of the crisis (Soledad Lorenzo, Oliva Arauna, Astarte, Distrito 4, Paula Alonso, Egam, Salvador Díaz, Inés Barrenechea, Astarte, Tolmo, La Nave, Espacio Líquido, Sandunga, Alex Telese, Durán, Alfama, Puchol ...) implies not only the consequent impairment in the income of artists, but also an important touch of alarm in the task of promoting and spreading the artist's work and career, a task associated with the activity of the gallery itself. One fact that does not appear in the Dr. McAndrew's reports but which is easily verified in the context of the market is that most of the galleries that have disappeared since the beginning of the crisis belonged to a concrete gallery profile, within the most classical contemporary art, supplying to a model of collector interested by that type of art, galleries whose activity within that style allowed the survival of the artists who created this type of art. The massive closure of galleries of this profile in such a short period of time, together with the closure of many other important contemporary art galleries,

4 While the 2012 report declares an approximate number of 3,500 registered art galleries (p.23), in the next report of 2014 the number of galleries registered is slightly more than 2,950 (p.27), a much lower figure than the data reflected two years earlier. 
has caused an absolute cataclysm in the economy of the artists who depended on the sales of their works in those galleries. It has, in short, caused that the artists associated to them have had to reorganize their careers to continue maintaining the artistic activity as their main source of income. Hence our interest in knowing what attitudes and aptitudes, tools and features, both personal and professional, under what circumstances and with what results, have marked this necessary exercise of resilience between our artists.

\section{The Concept of Resilience Associated to the Artistic Professional Activity}

We know that the first studies on resilience date back to the years after World War II (Grinker and Spiegel, 1945, quoted in Hobfoll [26], 308), and are focused on the analysis of people, namely soldiers exposed to the rigors of the conflict, which had suffered highly traumatic experiences, and allowed to observe how some of them, instead of succumbing to such situations, had managed to come out well and strengthened. In fact, resilience in soldiers and front line corps is still under study nowadays (Cohrs, Christie, White \& Das [13]). But it would not be until the 1970s when the resilient personality became a field of study for psychology. Kobasa and Maddi [34] propose how, in a situation of stress between the individual and the environment, certain characteristics of the subject's personality can generate resistance and increase the capacity for protection. The relationship between resilience and illness is especially significant since, as Kobasa and Maddi indicate in studying how the character of people affects the possibility of contracting certain ailments after suffering stressful situations, the way in which these particularities of the character contribute to maintain such people healthy would allow a better understanding of the essence of human well-being. Thus, a resilient character would cushion the harmful effects of a conflict situation and protect the individual against disease. Regarding whether resilience can be considered a lasting or even permanent faculty in the individual, there are several theories. On the one hand (Bonanno et al. [10]), it is considered that people who show resilience develop a certain capacity of endurance that confers a resistant character per se. However, other theorists (Hobfoll et al. [27]) have found that resilience tends to decrease in people who are subdued to continuous stress, such as persistent warfare or recurrent terrorist attacks (Cohrs, Christie, White \& Das [13]). Therefore, we find that resilience can have different levels and characteristics, depending on the individuals themselves, their abilities and predisposition, and also depending on the conditions of frequency, intensity and duration of the conflict situations that are seen submitted (Herrman et al. [25], Cheeseman [11]).

As Esther Menezes and Consuelo Morán point out in a recent study on this subject (Menezes and Morán [40]), there are many characteristics that define a resilient character, characteristics that sometimes come from one's own personality, or even from physical factors, and that in other cases are adopted depending on the difficult situations through which the individual is going through. In this context, it is interesting to recall Fonagy's theory (Fonagy et al. [18]) about the influence of environmental factors on the individual's innate personal characteristics that make him / her resilient, in the process of generational transmission of this characteristic. The study conducted by Morán (44) with a spectrum of 868 people consulted, served to define the resilient personality traits according to their importance:

1. Emotional Stability

2. Self-esteem

3. Extroversion

4. Self-control

5. High self-efficacy expectations

Thus, features such as self-control and high expectations of self-efficacy would be associated with others complementary to these and purely professional ones, described by Fonagy [18], such as planning ability, problem solving skills or conflict management, factors that individuals will develop throughout their lives, both personally and professionally. In fact, and as we are showing, given that resilience is considered as a process of development through which the individual passes in order to recover from the conflict situation and regain its operability and functional capacity (Cicchetti [12]), we can clearly find a relationship between the resilient personality and the professional activity, adapting characteristics of the first in the performance of the second. Thus, we can associate, as in the case at hand, attitudes and personality traits of those artists that we can consider resilient in the development of their activity and in their relationships with the sector, with galleries and other agents of the market, especially in those circumstances in which such relations are particularly difficult.

The proliferation of artistic collectives and co-creation projects in recent years in Spain suggests that there is a need to combine efforts in order to optimize resources and results and to develop new behaviors that facilitate subsistence. The traditional saying of "united we are stronger" could thus be applied to the artistic activity in our country. Equal reflection deserves the artists' connection with professional artists' associations, a fact that leads us to reflect not only on the role that artists' associations must play in favor of the sector, as a hinge between creators and other actors in the art system, but on how their role is appreciated by the artists themselves ${ }^{5}$. There is in Spain a

5 We are aware of the fact that in Spain the dependence on trade unions or associations, as well as other organizations for the protection of labor rights, relays on the resolution of certain situations or problems that require a more specific or professional solution than the worker himself can solve, so that the permanence in these entities depends, in many cases, 
certain lack of a historical tradition of professional associations, compared to other countries in which it is much more common ${ }^{6}$, especially in the artistic sector, where this structure is stronger and provides artists with consistent support in situations of risk. To give an example, in the USA there are organizations whose objective is to offer artists tools to support different risk situations. Aware of the precariousness and weakness of the creators sector, either at the individual level or through local professional or sectoral associations, in the face of certain problems that may hinder or impede their activity, the Craft Emergency Relief + Artists Association 'Emergency Resources' was born in 2006 together with SouthArts and ArtsReady the Coalition for Artists' Preparedness and Emergency Response [46], a coalition born from birth to provide artists with an organized support network for artists and associations that bring them together. From major catastrophes, pandemics or terrorist attacks to smaller, more sector-specific problems such as loss of work, material or documentation, legal assistance needs in cases of theft, forgery, intellectual property assault, claims against public protests towards controversial exhibitions or performances or, of course, the loss of subsidies, sponsorships, scholarships or financial aid, the drastic decline in artwork sales, or the need for business or marketing advice to redirect the artist's career in the market, are some of the areas in which the Coalition works to support creators, both individually and collectively, to be more resilient and better able to cope with unexpected problems. This Coalition, maintained with state funds and private sponsorships of a very different nature, has been applied in recent years in the creation of a support network for artists and organizations that offers them planning and preparation guides for crisis situations, specific training, a team of professional assistants in different fields, logistical support at technical, material or intermediary level. Faced with a contingency, the artist feels in this way assisted and finds it much easier to overcome, relocate and move forward. In Spain, however, the lack of a structure at the national level that supports and encourages it, makes the fabric of Spanish associations weak and depends almost exclusively on the workers and partners themselves and their management.

on the solution of the problem or the need for advice. The lack of a clear awareness that an association is formed by its own associates, and that the mere permanence is already a way of strengthening its structure in support of its members, may be one of the reasons for this detachment.

6 The article by Lola L. Muñoz in the online magazine Los Replicantes, entitled "Trade unions in Spain: low affiliation, low representativeness", points to the decline in membership levels and the loss in representation percentages of the two major unions in Spain during the last years, and the great difference with respect to other countries of our European environment. "Denmark, Finland, Sweden and Norway have the highest membership rates in the European Union. Compared with $16 \%$ of the Spanish case, $80 \%$ of Danish workers are union members, $74 \%$ are Finnish, 78\% are Swedes and 53\% are Norwegians. In the Nordic countries, the system is far more different from the Spanish one: the agreements negotiated by the unions only affect their affiliates (retrieved from

http://www.losreplicantes.com/articulos/sindicatos-baja-afiliacion-poca-r epresentatividad/)

\section{Methodology and Results}

The main purpose of our study is to know the circumstances in which the artist, as creator and as part of a society in a state of permanent change and in a sector forced to adapt to new often unstable structures, develops his / her professional activity. The systematic observation ${ }^{7}$ that we have been able to carry out from within the system (Neuman, 1994; Grinell, 1997), the analysis of the role that each actor of this sector plays in the framework of relations that sustains the artistic activity in our country, and the evolution of which we have been aware during the last decade, have allowed us to appreciate how, in the current socio-economic situation that our country is experiencing, the artist adopts a new role that in turn is linked to all agents of the system to which it belongs, and which it conditions at the same time, so that it adopts a different dimension that needs to be analyzed. In order to achieve this objective, we designed a plan of action that served as a guide through the different phases it consisted on. As we will see further on, the review of the existing literature and the studies on this sector carried out in other countries during the last years gave us a first contact with the general situation of creators in our time, an overview that would have to be endorsed with a detailed study of the artistic creation sector in our country and at the present time, through a rigorous research process based on data provided by the artists themselves in a survey, a fundamental source for this research (Yapu [61]).

The lack of a census that provides concrete data on the number of plastic and visual artists with professional activity in Spain makes it difficult to quantify the population of our study. The analysis of the existing literature (McAndrew [37-39], Eurostat [15], AAVC [1] $)^{8}$, combined with an in-depth study of those records that in our country include artists for their tax activity (Tax Agency, Social Security, National Employment Institute), as well as the databases of the numerous professional

7 The observation of the Spanish art system reality and, in particular, the evolution and dynamics of the art market and its relation with artists as generators of the whole process, has been in the genesis of our study for more than twenty years, intrinsically linked to our professional development. The methodology followed in that first phase, even before we knew that it would be the beginning of our research, sought to collect and analyze data that allowed us to understand reality at any time, to explain it in the space-time context and to venture its evolution in the short term. We developed the first years of our study on this observation structure (Creswell, 1997), looking for that the subjective reality, born from the individual and sectoral experience of our study group, which helped us to pose the questions that we would elucidate in our research and to discover the objective reality of this sector.

8 The different sections of the International Standard Classification of Occupations 2008, organized by the International Labor Organization, the National Employment System CO-SISPE, the State Employment Service SEPE (former National Employment Institute INEM), the National Classification of Economic Activities or CNAE of the National Institute of Statistics and the Tax of Economic Activities IAE registered by the Ministry of Finance and the Tax Agency, usually group plastic and visual artists with other professionals from the cultural industries, writers, actors, interpreters, etc. Therefore, the data that these instances have contributed to our research between February and June 2017 may not be accurate in quantifying plastic and visual artists, but they have been taken into account for our estimation 
associations of artists existing in all our territory, has led us to determine that the total number of plastic and visual artists active in our country can be located around the 25,000 artists. If we consider this data as the size of our population, and based on the Arkin and Colton (1962) table, using a $95 \%$ confidence level with a maximum error of $3 \%$, the size of our sample should be not less than 1,064 individuals.

In order to obtain the data, after having defined the research questions that we hoped to solve in our study, and once the corresponding hypotheses were presented, an exhaustive survey was made up of 42 questions divided into three large groups, "About the artist "," On the economics of the artist "and" On the relationship of the artist with the market ". After a period of test and evaluation of the survey with different professionals of the sector, we began the period of data collection that would comprise the months of May to September of 2016, period in which it was expected to obtain the previously described sample. However, the final sample exceeded this amount, reaching to collect data of 1,164 artists. Of these, 5.3\% were excluded from this study, either due to incoherence or errors in the data provided, or because their surveys were not fully completed. The remaining $94.7 \%$, a total of 1,105 individuals, resulted in the final sample on which our study was based. In this way, taking into account the table of Arkin and Colton mentioned above, we guaranteed a level of confidence of $95 \%$ with a maximum error of $3 \%$ and, therefore, a high degree of precision.

Regarding the degree of internal control that we would apply as a research strategy (Castro and Gutiérrez, 2016: 79), we opted for a selective research design based on the different decisions that would be taken in the process, some of them already mentioned: operation of variables, establishment of the sample, conditions and period of collection of data, etc. The selective modality exerts an average control over the situation, tends to study the data and phenomena under their natural presentation and not to intentionally manipulate the levels of the independent variable, studying the subjects according to how they react to the different variables. The selective design allowed us to describe the reality of our study sector from the data obtained, identify regularities in those data and venture predictions or causal relationships where one or more variables could be considered antecedents of others, as we will see that in fact occurred.

The results from the data contributed by the artists in this survey should allow us to diagnose if the characteristics of a resilient personality that we have analyzed previously can be applied to that profile of artist and to what extent, and if we can indeed speak of resilience when we refer to the attitudes and way of working of Spanish artists who have suffered a certain impairment in their economy and career as a result of the current economic crisis.

Among all the artists who participated in our survey, we selected those whose age exceeds 40 years, a total of 588 artists who, therefore, were more likely to have develop their artistic activity since before 2008 and therefore suffered the effects of the crisis in its economy (figure 1: Age). We have detected that this age group is of special importance in our study, reaching $52 \%$ of the artists surveyed, more than half, therefore. Hence the results that emerge from their responses are especially significant.

We see from the graphs that the proportion between men and women is very similar (figure 2: Gender), and that the distribution by regions in Spain also responds to the population in each one of them, finding more answers in more populated communities such as Madrid, Andalusia or Catalonia, but also representing smaller communities or with a lower population index such as La Rioja, Navarra or Extremadura (figure 3: Geographical distribution of artists in Spain).



Figure 1. Age 




Women
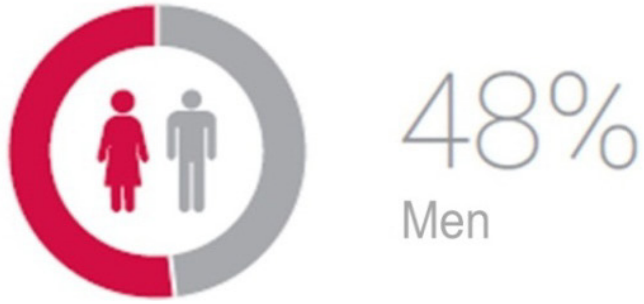

Men

Figure 2. Gender



Figure 3. Geographical distribution of artists in Spain

With regard to the number of years dedicated to the artistic activity (figure 4: Number of years dedicated to artistic activities), we have found $6.3 \%$ of artists who have been working for less than 5 years, which has surprised us, since we are referring to artists over 40 years of age. Our intention in segmenting the artists of this age group was to focus on those individuals with a longer trajectory, but we consider that this data should also be present in our study. On the other hand, only $20.9 \%$ of the artists interviewed over 40 years of age have more than 35 years of artistic activity. This information, however, takes on special significance when compared to the ones we will see further on.

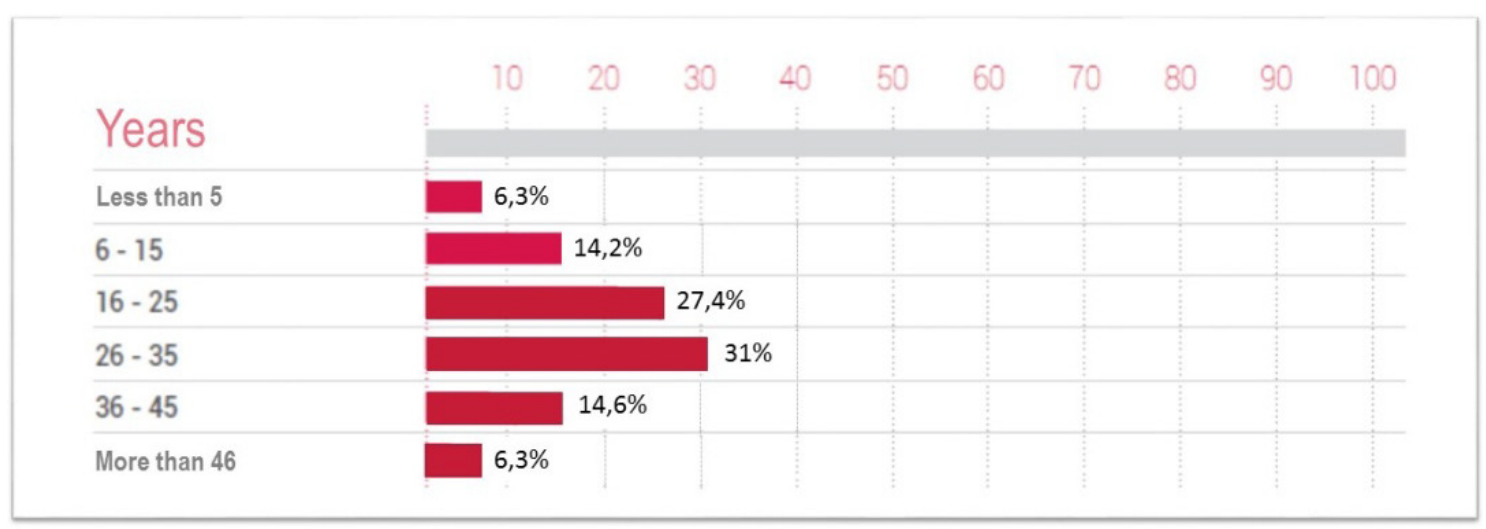

Figure 4. Number of years dedicated to artistic activities 
The answer on how many of the years devoted to his artistic activity they have contributed to the Spanish Social Security System (figure 5: Number of years contributing to the Social Security System) gives us the guideline of whether this activity can be considered as a source of income, that is, as a professional activity. $88.5 \%$ of artists over the age of 40 have contributed less than 15 years to Social Security for this activity: again, the precariousness and lack of regularity in the income for the artistic, along with the high quotas to pay, cause that, at times, the artist does not declare his / her activity as a source of income, since it cannot be considered as such. As for the fiscal situation of artists (figure 6: Professional tax status), the figures are similar to the results, with one-third of self-employed individuals and almost a third of unemployed, and $12.7 \%$ of individuals retired. It is interesting to take into account two aspects: first of all, artists who are described as self-employed state that they do not quote the Social Security contribution on an ongoing basis, but only on the occasions when they obtain income from their activity, which limits the regularity of this contribution, concerning future retirement benefits. On the other hand, after the last reform of 2013, the minimum amount of 35 years and nine months quoted, which is what is needed today in Spain to guarantee a retirement pension, will gradually increase until reaching 38 years in 2027. Taking into account that among our respondents, only $10.9 \%$ are able to quote as self-employed every month, and that $26.6 \%$ are only allowed to quote when they have income, we understand the reason for this small link with Social Security in our country, which makes difficult to secure future benefits. Therefore, of all the artists who have participated in our study, a minimum number of individuals will be entitled to the benefit for retirement. Therefore, the group of artists who have responded to our survey and whose ages are currently over 60 will have serious difficulties in being able to retire as artists.

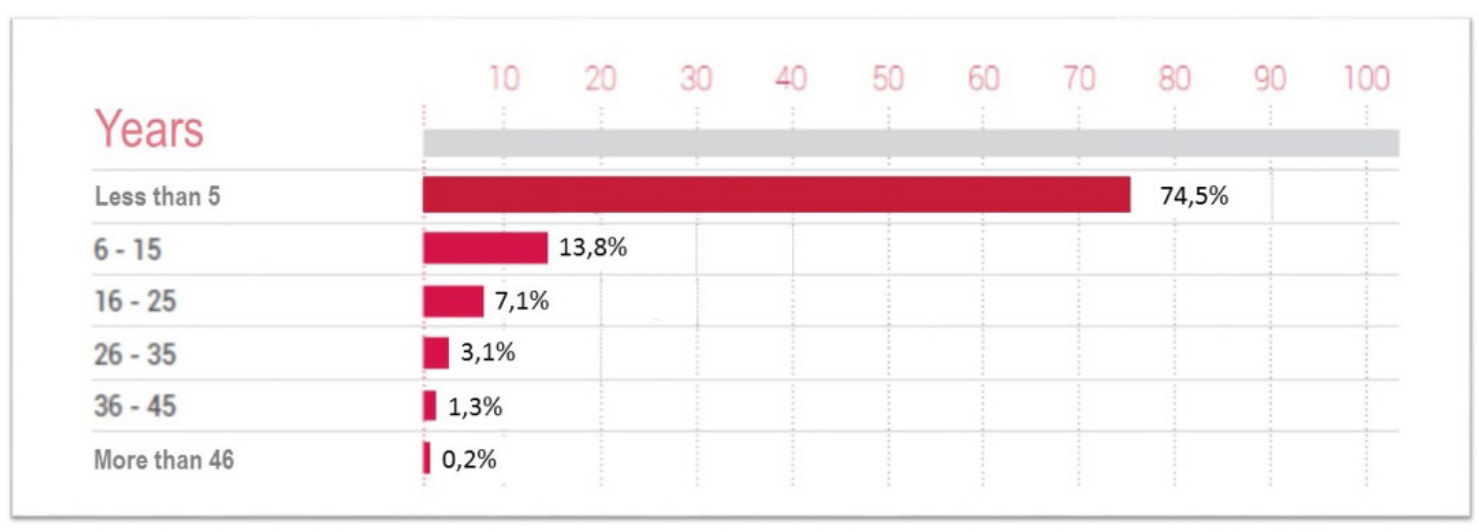

Figure 5. Number of years contributing to the Social Security System

\begin{tabular}{|c|c|c|c|c|c|c|c|c|c|c|}
\hline Status & $\begin{array}{c}10 \\
\vdots\end{array}$ & $\begin{array}{c}20 \\
\vdots\end{array}$ & $\begin{array}{c}30 \\
\vdots\end{array}$ & $\begin{array}{c}40 \\
\vdots\end{array}$ & $\begin{array}{c}50 \\
\vdots\end{array}$ & $\begin{array}{c}60 \\
\vdots\end{array}$ & $\begin{array}{c}70 \\
\vdots\end{array}$ & $\begin{array}{c}80 \\
\vdots\end{array}$ & $\begin{array}{c}90 \\
\vdots\end{array}$ & $\begin{array}{c}100 \\
\vdots\end{array}$ \\
\hline & & & & & & & & & & \\
\hline Public employee & & $14,4 \%$ & & & & & & & & \\
\hline Entrepreneur & $1,7 \%$ & & & & & & & & & \\
\hline Self employed / freelance & & & & & & & & & & \\
\hline Part time / fulltime worker & & $14,4 \%$ & & & & & & & & \\
\hline Unemployed & & & $24,9 \%$ & & & & & & & \\
\hline Retired & & $7 \%$ & & & & & & & & \\
\hline Other & $1,5 \%$ & & & & & & & & & \\
\hline
\end{tabular}

Figure 6. Professional tax status

One of the elements that, as we have mentioned before, characterize resilience as a capacity to overcome adversity is the combination of psychological aspects of the individual with social and professional aspects that can influence his career. Therefore, among the questions of our survey, we were interested in knowing the response of our group of artists regarding their participation in professional associations. We have previously mentioned the role of associations of artists in our country in the defense of their rights, in information and training on tools necessary for the good development of 
their career, etc. Therefore, within the group of artists over 40 years of age in our study (figure 7: Participation in professional associations), the average number of artists currently associated was significantly higher than the global average, $45.2 \%$ compared to $39.9 \%$ overall, and $24.1 \%$ been associated in the past compared to $20.2 \%$ overall, which also gave us evidence of how this sector is aware of the need and the usefulness of participating in these professional groups, a new tool to promote the resilience of our artists.



Figure 7. Participation in professional associations

The percentage of income from artistic activities within the total income of artists in our group is also quite peculiar (figure 8: Approximate income from artistic activities). More than three-quarters, 77.4\%, state that these revenues do not exceed $40 \%$ of their total income, that is, they must fill these gaps with other lucrative activities unrelated to the performance of their artistic work. Nevertheless, the economic precariousness of the artists is also evident in this age group (figure 9: Approximate income level [all activities included]): an alarming 38.2\% of the artists surveyed do not reach $8,000.00 €$ per year, that is, they stand for below the inter-professional minimum wage in Spain ${ }^{9}$.

\begin{tabular}{|c|c|c|c|c|c|c|c|c|c|c|}
\hline & 10 & 20 & 30 & 40 & 50 & 60 & 70 & 80 & 90 & 100 \\
\hline Incom & : & I & ! & i & 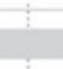 & & 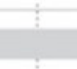 & : & : & : \\
\hline 0 to $20 \%$ & & & & & & & 68,6 & & & \\
\hline 20 to $40 \%$ & $8,8 \%$ & & & & & & & & & \\
\hline 40 to $60 \%$ & $4,3 \%$ & & & & & & & & & \\
\hline 60 to $80 \%$ & $3,2 \%$ & & & & & & & & & \\
\hline 80 to $100 \%$ & & $15 \%$ & & & & & & & & \\
\hline
\end{tabular}

Figure 8. Approximate income from artistic activities 


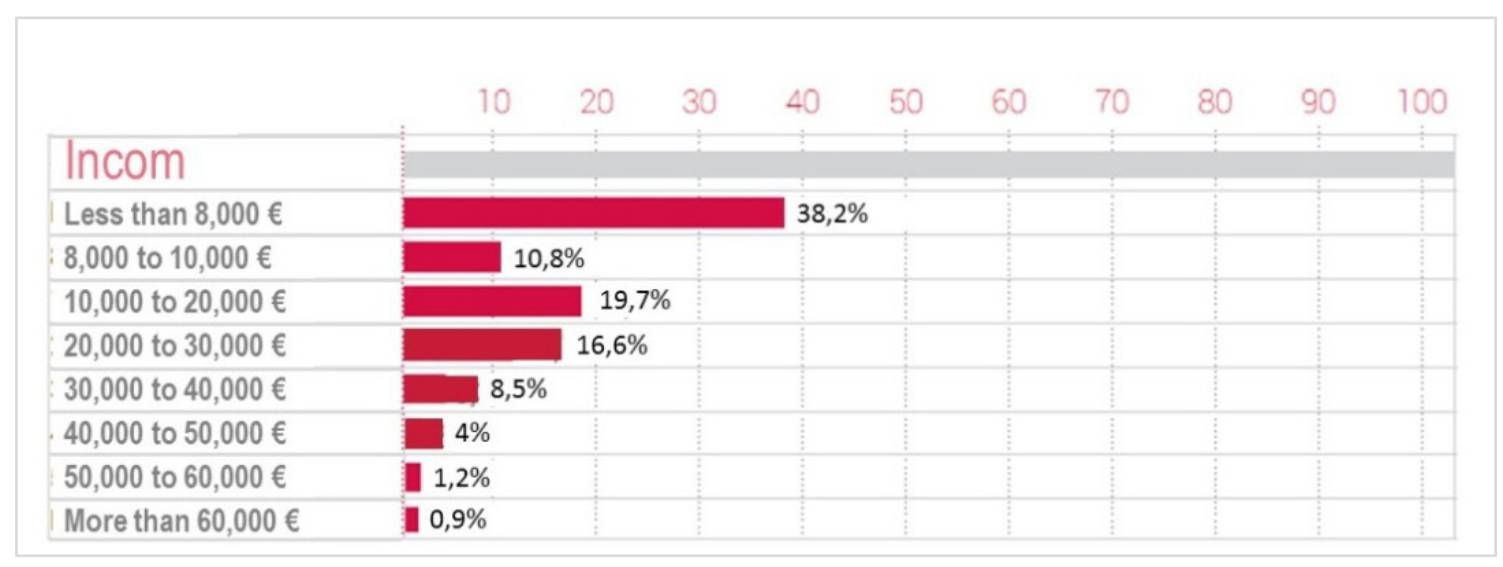

Figure 9. Approximate income level (all activities included)

An important fact that determines the degree of professionalism of the artists is the participation in exhibitions, a fact that places the creator in the artistic scene, and lets both the public and critique get to know his/her work, whether recent or anthological. We are interested in knowing specifically how this exhibition activity has been developing during the last two years, taking into account the different formats that these exhibitions can have, from shows in the artist's own atelier or in alternative spaces, public places, galleries, museums, etc. Among the different questions in our study related to this activity, we were interested in knowing mainly what percentage of artists over 40 years of age maintained their exhibiting activity. Faced with this question, the vast majority, 82.7\%, answered yes (figure 10: Artists who have exhibited during the last two years). However, on the question of whether such exhibitions had served to sell the exhibited works (figure 11: Artists who have sold artworks during the last two years), only $55.6 \%$ said yes. Once again, we find that the fact of exhibiting is not always linked to the fact of selling the work of art, which affects the difficulty to make the work of the artist profitable as a source of income from his /her professional activity.

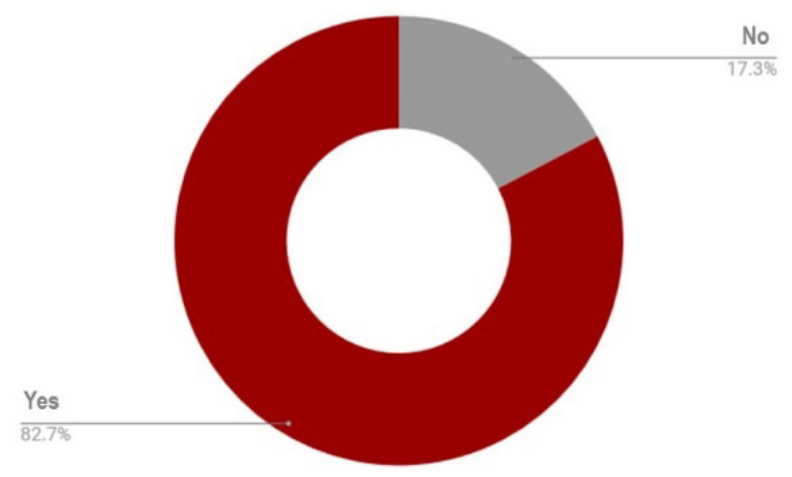

Figure 10. Artists who have exhibited during the last two years

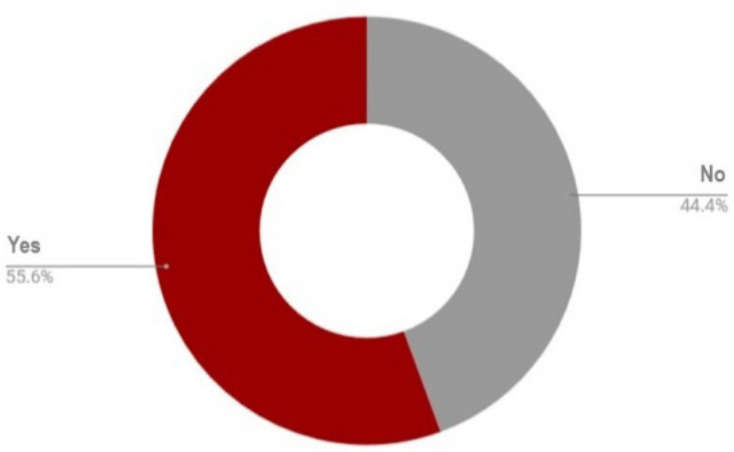

Figure 11. Artists who have sold artworks during the last two years 
At this point, it was necessary to know two basic questions in the exhibition activity of the artist since the beginning of the crisis: first, its linkage to commercial galleries, taking into account that this type of exhibition space is the most suitable for commercialization of the work; second, to what extent the artist's link with his /her reference galleries continued to maintain the ability to generate income. Therefore (figure 12: Artists with a stable relationship with art galleries since 2008), we were surprised to see that $65 \%$ of the artists surveyed answered negatively, that is, either they had never maintained stable relationships with galleries or dealers, or these relationships had ceased since 2008. The remaining 35\%, those artists who did maintain stable relationships with art galleries, were asked how they considered their current situation, in relation to the income received from the sale of their art through their reference galleries (figure 13: ¿How do you consider your current selling situation in art galleries, in relation with the period before 2008?). Apart from the $22.5 \%$ that considered it the same, $68.3 \%$ stated that it was worse to a greater or lesser extent. Only $9.2 \%$ of the artists surveyed stated that their sales situation related to their galleries had improved in recent years compared to the pre-crisis period.

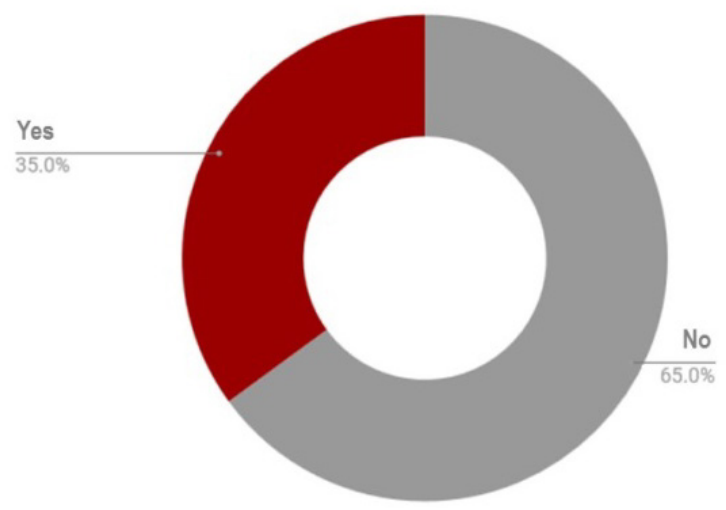

Figure 12. Artists with a stable relationship with art galleries since 2008

\begin{tabular}{|c|c|c|c|c|c|c|c|c|c|c|}
\hline & 10 & 20 & 30 & 40 & 50 & 60 & 70 & 80 & 90 & 100 \\
\hline \multicolumn{11}{|l|}{ Situation } \\
\hline $100 \%$ worse & \multicolumn{4}{|c|}{$32,9 \%$} & & & & & & \\
\hline $75 \%$ worse & \multicolumn{3}{|c|}{$14,6 \%$} & & & & & & & \\
\hline $50 \%$ worse & \multicolumn{3}{|c|}{$13,3 \%$} & & & & & & & \\
\hline $25 \%$ worse & $7,5 \%$ & & & & & & & & & \\
\hline Same & \multicolumn{4}{|c|}{$22,5 \%$} & & & & & & \\
\hline $25 \%$ better & $4,2 \%$ & & & & & & & & & \\
\hline $50 \%$ better & $3,3 \%$ & & & & & & & & & \\
\hline $75 \%$ better & $1,3 \%$ & & & & & & & & & \\
\hline $100 \%$ better & $0,4 \%$ & & & & & & & & & \\
\hline
\end{tabular}

Figure 13. How do you consider your current selling situation in art galleries, in relation with the period before 2008 ?

The incorporation of the artists to the new technologies for communication matters during the last years is evident, according to the data contributed in our study. The use of the different channels that the network offers is being used by our creators in all their magnitude, and it is difficult to find artists who do not manage them with some fluency. Many of the artists surveyed state that they personally maintain specific channels appropriate to the media they work with, such as YouTube, Vimeo, SoundCloud or SonicPlug for video artists, for example, which means that, on many occasions, these channels associated with blogs and social networks, all free of charge, have taken the place of web pages that were generalized in the 90 s and which, although low, have a cost and require maintenance.

It is, therefore, in the very person of the artist where the tasks of defining and communicating his digital identity and dissemination of his artistic career lie. As we have seen, tasks that even the generalization of digital culture and the use of transmedia networks fell into galleries and dealers, are now managed directly by the creators.

If we re-segment the artists surveyed in our study into two large groups, younger than 40 and mature artists (figure 14: Online communication channels management: comparative between artists older and younger than 40), 
and compared their use of networks, we also see certain differences that characterize younger artists. These access social networks more frequently, manage transmedia channels more often, as well as their own websites and blogs. On the contrary, the more mature artists are those who more habitually outsource their presence in the network and put themselves in the hands of professionals or people of confidence. However, it should be noted that among older artists, the need to access the digital world as a channel not only for communication but also for sale has become widespread. In contrast to the younger population, the generation of artists that are the object of our study has become increasingly used to the use of new technologies, appreciating the usefulness that the use of digital channels for the circulation and sale of their works can provide in a moment in which the sale of the work of art by channels hitherto traditional has decreased significantly, as we will see later on.

One of the significant changes in the Spanish market originated by the crisis of 2008 , the closure of many galleries in the following years and the loss of the main source of income for many artists, is the search for other marketing channels for their work. In our survey, the question about the different sales channels of artists over 40 years of age also yielded interesting data (figure 15: Source of income from artwork sales). Although the sale through galleries continues to have importance, we see how the direct sale by the artist increases, either to collectors or institutions or through fairs of independent artists, fairs in which the figure of the gallery owner or the art dealer does not participate. In addition, as we saw before, internet sales are consolidated, a channel that does not require intermediation when it is managed directly by the artist. The increasing access of artists to new technologies and electronic sales resources allow them to market their work and thus maintain an alternative and growing source of income, while consolidating the presence of the artist in the networks and their ability to establish new channels of diffusion and sale, connections with new galleries and with other agents of the art system.

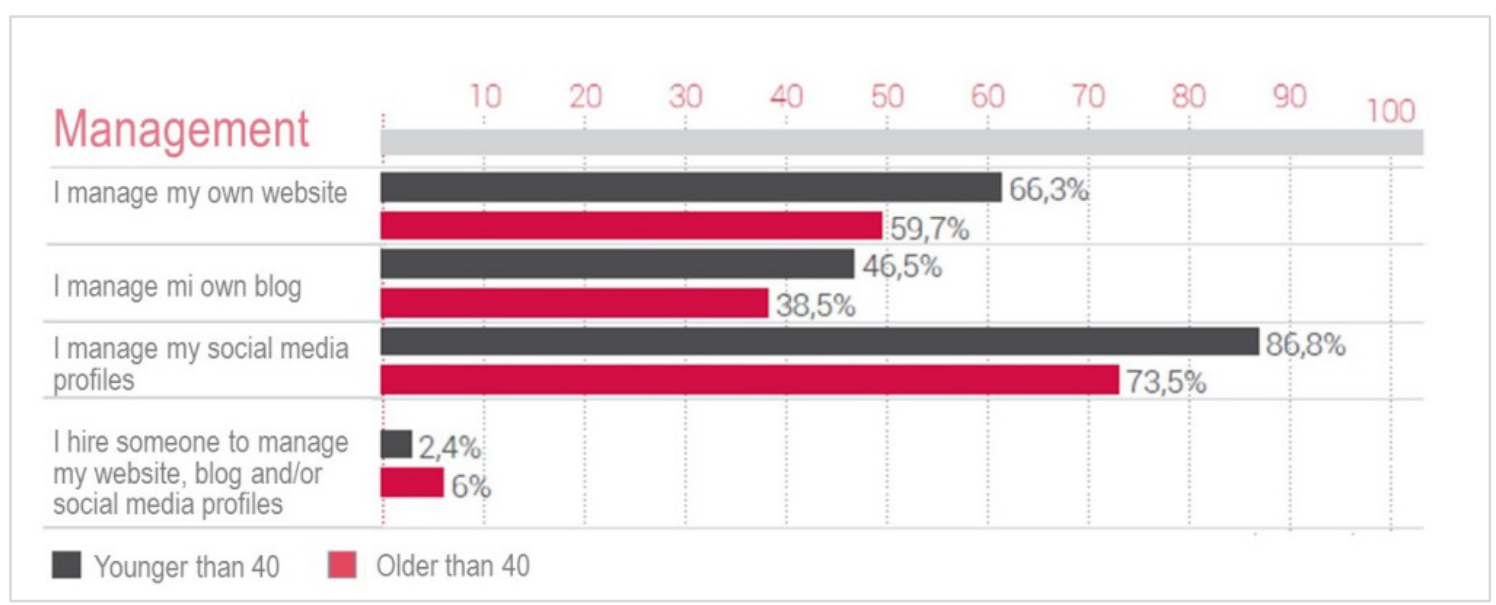

Figure 14. Online communication channels management: comparative between artists older and younger than 40



Figure 15. Source of income from artwork sales 


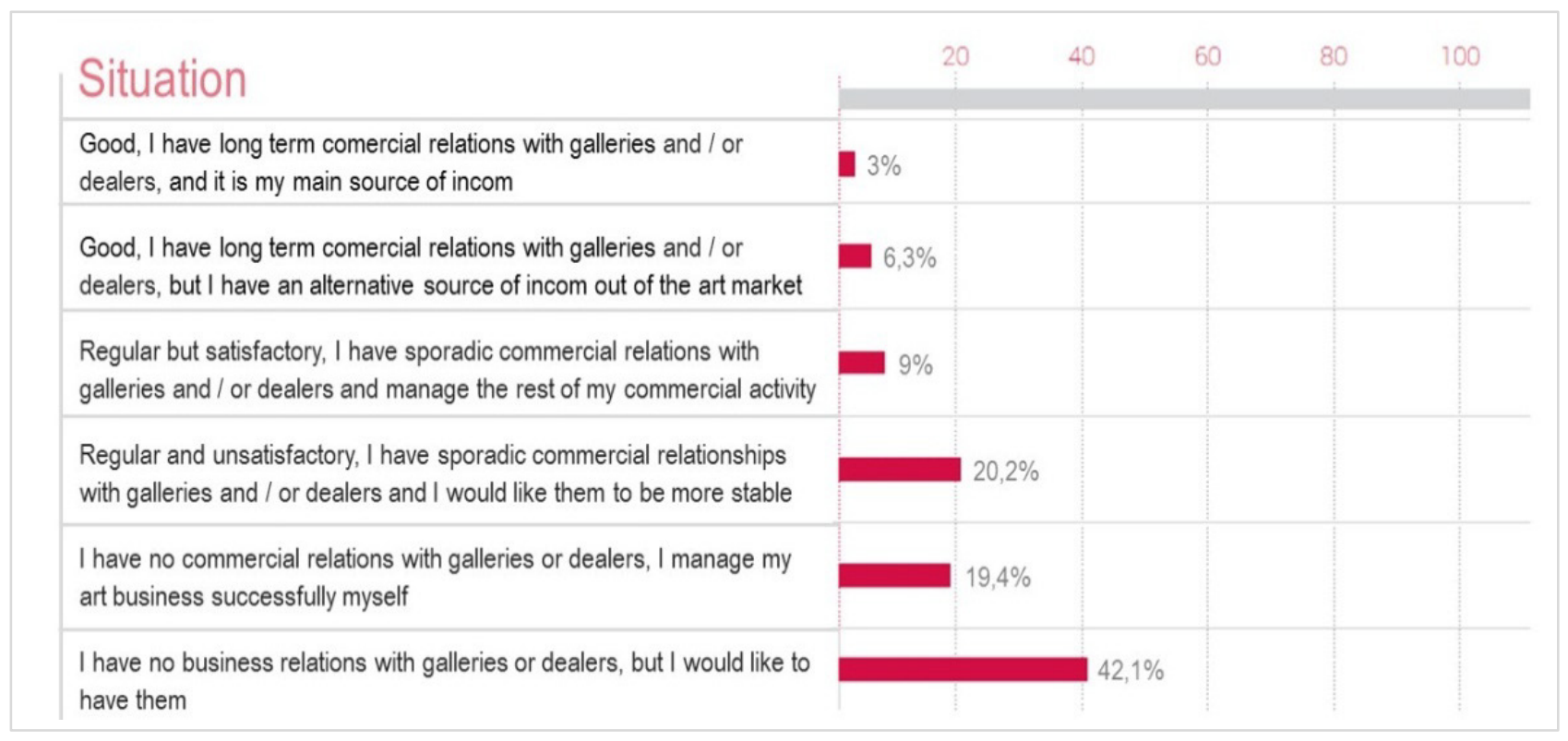

Figure 16. How do you consider your current situation, in relation with the art market?

Finally, and as a colophon to understand the reality of the situation of Spanish artists in this age group, we wanted to know their subjective assessment of their situation, establishing six possible responses based not only on how they considered their relationship with the market, but also on their expectations for the future. For this, they were asked a question that offered these six variants (figure 16: ¿How do you consider your current situation, in relation with the art market?). The results of this question in the group of artists over 40 , although very close to the overall results, show certain particularities that demonstrate how this group of artists is not only taking concrete steps to develop their career despite the current crisis of the market, but are more satisfied than average with the results they achieve. In short, it reaffirms us in the capacity of resilience of this group of artists.

Just as in the overall results, only $3 \%$ of the respondents over 40 declared themselves to have a good relationship with the market, being this their main source of income, and also $6.4 \%$ of the artists also maintained a good relationship with the market, but obtained its income from another alternative source outside the artistic activity. However, the group of artists who considered their situation regular and satisfactory, with sporadic relationships with galleries and / or dealers and managing them the rest of their commercial activity, is slightly higher than the global average, $9 \%$ compared to $8.3 \%$ overall. Likewise, the group of artists who declared that they did not have any commercial relationship with galleries but did manage their commercial activity satisfactorily was also somewhat above the global average, $19.4 \%$ compared to $18.3 \%$ overall. Finally, artists dissatisfied with their relationship with galleries were below average, 20.2\% compared to $21.4 \%$ overall, and artists with no relation to galleries but who wanted to have them was also five tenths lower in our group, $42.1 \%$ compared to $42.6 \%$.

Therefore, in this last group of answers we already find some data that tell us not only about the capacity of reorientation of their career in the group of artists who have endured the crisis, and the confidence that these artists continue to maintain in the art market, although it is evident the difficult situation that the trade of the artwork is currently going through in our country, but also of the confidence in their own capacity to look for effective alternatives in new channels of diffusion and sale of their work and, mainly, to maintain control over their career.

\section{Conclusions}

Throughout the research about the economic activity of artists in Spain, our main objective was to approach the situation in which Spanish artists live and work today based on their own testimony, which has been verified with specific data, and we have also been able to know and understand each profile of artist in our country with all the nuances that define it and characterize it, its needs and demands, as well as its aspirations and objectives at a professional level. Thanks to the commitment of the artists consulted to inform us of their situation, the conclusions we have reached draw an image that we believe to be real and concrete in this sector in Spain today.

The labor circumstances of the artists who participated in our study make it clear that their activity poses more inconveniences than advantages: mostly self-employed workers with a high degree of unemployment, with incomes that often barely reach the inter-professional minimum wage, with serious difficulties to face the usual expenses and with less capacity than the national average to face a mortgage or to look after dependent people, with 
few years of contribution to the Social Security System and with the consequent insecurity towards future retirement benefits. As it has been verified throughout our research, the data that we have known have offered us a very truthful portrait of the artist as an autonomous worker in a really precarious situation that is not unique to the visual artists, since they share this precariousness with many other creators of the cultural industries, and that possibly will take its toll on the cultural development of our country. Unlike any other professional, who engages in his /her activity while receiving a retribution for it or changes his her work according to their needs and circumstances, the artist continues to create, perhaps out of necessity, because the creative drive is stronger than the economic needs. The exhibition activity has not been abandoned even in the most delicate moments of the crisis, even when the reference galleries have disappeared and the artists have had to find alternative spaces or their own ateliers to show their work, participating in shared projects, reducing the costs to the maximum, seeking financing in crowdfunding projects, in co-creation, showing a generosity and a desire to share their activity with society worthy of the highest recognition.

Hence, we believe that the data that our research reveals will allow us, in fact, to diagnose those characteristics of the resilient personality in Spanish artists, especially those individuals who developed their artistic career in the years prior to the economic crisis of 2008 and who, using social and professional tools, and relying on his own ability to excel, have been able to reorient their careers and maintain their artistic activity as a source of income. If resilience may be defined as a process of disruption by life events, by professional adversities and challenges, and the development of self-mastering strengths to grow stronger through the disruption, we find that certain Spanish artists prove to have those strengths. The elements that, in our opinion and based on the results obtained in our study, allow us to characterize the profile of this resilient artist are the following:

- Psychological: the appreciation of the artists surveyed in our study and belonging to the group of over 40 years, based on the data they have provided, show evidence of a greater degree of satisfaction with their work and the development of their career in relation to the global average. This fact can be related to the idea, manifested as we have seen in the existent literature, which artists generally develop a higher degree of satisfaction for their professional activity, in spite of the professional difficulties that they have to cope with. In addition to the influence of exogenous elements, we can consider, according to the information provided by the own artists of our group, that the artistic activity itself, the artistic vocation, favors a positive character before the professional development and a greater capacity of resistance to face difficulties.
- Social: the development of collaborative art projects, co-creation, work in artistic collectives and groups, together with participation in professional associations and the joint struggle to defend the activity of artists, are factors that positively influence the improvement of difficult situations through collaboration among professionals. As we have also seen, social recognition and support among artists, whose work is often eminently autonomous, favor the capacity to overcome professional crises and stimulate the feeling of belonging to the artistic collective.

- Professional: facing the art market crisis in Spain, artists with an established career who have seen their income decrease have in many cases opted to reorient their strategies. Most of them have opened up new ways of dissemination and communication, and new forms of access to market agents, have entered the new technologies with determination and good judgement, controlling their brand image successfully. The appreciation of this group of artists regarding their relations with the market is more positive than the average of our study, which leads us to think that they have indeed developed a high capacity to assume this important change in their careers.

Therefore, the results of our research allow us to reaffirm ourselves in our initial hypothesis. The sample of artists who contributed to our survey, 588 out of the more than 1,100 participants in this study, is a significant sample, and the data provided offer, as we have seen, very relevant conclusions. In turn, it sets out a solid and necessary framework for, starting from here, delving into other aspects that influence their resilience in maintaining their artistic activity as a modus vivendi.

\section{REFERENCES}

[1] AAVC (2006). La dimensión económica de las artes visuales en España. Barcelona (España): Associació d'Artistes Visuals de Catalunya.

[2] Abbing, H., (2002), Why are artists poor? Amsterdam (Holland): Amsterdam University Press.

[3] Adler, M. (2006). Stardom and Talent. In Ginsburgh, V. A., \& Thorsby, D., (Eds.), Handbook of the economics of arts and culture. Amsterdam (Holland): North-Holland.

[4] Anthony, E.J y Cohler, B.J. (1987). (Eds.) The invulnerable child. New York (USA): Guilford Press.

[5] Bağcioğlu, N. (2016). Artistic labour: seeking a utopian dimension. Cadernos de Arte e Antropologia, 5(1), 117-133.

[6] Barney, J. (1999): "How a firm's capabilities o affect boundary decisions. Sloane Management Review, primavera, 137-145. 
[7] Bass, E., Milosevic, I., \& Eesley, D. (2015). Examining and reconciling identity issues among artist-entrepreneurs. Cultural Entrepreneurship in Theory, Pedagogy and Practice, 99.

[8] Bille, T., Løyland, K., \& Holm, A. (2017). Work for Passion or Money? Variations in Artists' Labor Supply. Kyklos, $70(3), 347-380$.

[9] Bille, T., \& Jensen, S. (2016). Artistic education matters: survival in the arts occupations. Journal of Cultural Economics, 1-21.

[10] Bonanno, G., Westphal, M., \& Mancini, A. (2012). Loss, Trauma, and Resilience in Adulthood. Annual Review of Gerontology \& Geriatrics, 32, 189.

[11] Cheeseman, S. (2010). Single Mothers' Experience and Resilience [PhD dissertation]. Joondalup (Australia): Edith Cowan University.

[12] Cicchetti, D. (2010). Resilience under conditions of extreme stress: a multilevel perspective. World Psychiatry, 9 (3), $145-154$.

[13] Cohrs, J. C., Christie, D. J., White, M. P., \& Das, C. (2013). Contributions of positive psychology to peace: toward global well-being and resilience. American Psychologist, 68(7), 590.

[14] Dekel, T. (2014). At (art) work value: gendered aspects of income and livelihood, the case of women artists in Israel. Hagar, 11(2), 83.

[15] Eurostat (2011). Cultural statistics. Luxemburg: Publication Office of the European Union.

[16] Filer, R. K. (1986). The "Starving Artist"--Myth or Reality? Earnings of Artists in the United States. Journal of Political Economy, 94(1), 56-75.

[17] Fletcher, D., \& Sarkar, M. (2013). Psychological resilience. European Psychologist, 18, pp. 12-23.

[18] Fonagy, P. Steele, M., Higgitt, A. y Target, M. (2006). The Emanuel Miller Memorial Lecture 1992. The Theory and Practice of Resilience. Journal of Child Psychology and Psychiatry, 35, 2, 231-257.

[19] Frey, B. S., \& Pommerehne, W. W. (1989). Muses and Markets: Explorations in the Economics of the Arts. Oxford (UK): Blackwell.

[20] Galenson, D. W. (2000). The careers of modern artists. Journal of Cultural Economics, 24(2), 87-112.

[21] Gill, R. \& Pratt, A. (2015). The precarious Labour in the Field of Art, ON Curating 026: Issue 16/13, p. 26.

[22] Grant, M.F. et al (1996): Dirección estratégica: conceptos, técnicas y aplicaciones. Madrid (Spain): Cívitas.

[23] Greene, R., \& Greene, D. (2009). Resilience in the Face of Disasters: Bridging Micro- and Macro-Perspectives. Journal of Human Behavior in the Social Environment, 19 (8), 1010 1024. [Online] URL

http://www.tandfonline.com/toc/whum20/current

[24] Guo, T., y Tsui, M. (2010). From resilience to resistance: A reconstruction of the strengths perspective in social work practice. International Social Work, 53, 233-245.
[25] Herrman, H., Stewart, D., Diaz-Granados, N., Berger, E., Jackson, B., \& Yuen, T. (2011). What Is Resilience? Canadian Journal of Psychiatry, 56 (5), 258-265.

[26] Hobfoll, S. (2002). Social and Psychological Resources and Adaptation. Review of General Psychology, 6 (4), 307-324. [Online] URL http://www.apa.org/pubs/journals/gpr/

[27] Hobfoll, S., Palmieri, P., Johnson, R., Canetti-Nisim, D., Hall, B., \& Galea, S. (2009). Trajectories of Resilience, Resistance, and Distress during Ongoing Terrorism: The Case of Jews and Arabs in Israel. J Consult Clin Psychol, 77 (1), 138-158.

[28] Hulst, T. (Ed.) (2017). A History of the Western Art Market: A Sourcebook of Writings on Artists, Dealers, and Markets. Oakland, CA (USA): University of California Press.

[29] Hunter, C. (2012). Is resilience still a useful concept when working with children and young people? Australian Institute of Family Studies. [Online] URL http://www.aifs.gov.au/cfca/pubs/papers/02/02e.html

[30] Kay, J. (1993): "La estructura de la estrategia". Harvard-Deusto Business Review, no 57, p. 34-44.

[31] Karttunen, S. (2001). How to make use of census data in status-of-the-artist studies: Advantages and shortcomings of the finnish register-based census. Poetics, 28(4), 273-290.

[32] Karttunen, S. (1998). How to identify artists? Defining the population for 'status-of-the-artist' studies. Poetics, 26(1), $1-19$.

[33] Klamer, A. (1996). The value of culture: on the relationship between economics and art. Amsterdam (Holland): Amsterdam University Press, coop.

[34] Kobasa, S. C. y Maddi, S. R. (1977). Existential personality theory. Em R. Corsini (Ed.), Current personality theories (pp. 242-276). Itasca, IL (USA): Peacock.

[35] Kuhn, T. (1971). La estructura de las revoluciones cientificas. Mexico (Mexico): Fondo de Cultura Económica.

[36] Lena, J. C., \& Lindemann, D. J. (2014). Who is an artist? New data for an old question. Poetics, 43, 70-85.

[37] McAndrew, Clare (2012). El mercado español del arte en 2012. Barcelona (Spain): Fundación Arte y Mecenazgo.

[38] McAndrew, Clare (2014). El mercado español del arte en 2014. Barcelona (Spain): Fundación Arte y Mecenazgo.

[39] McAndrew, Clare (2017). El mercado español del arte en 2017. Barcelona (Spain): Fundación Arte y Mecenazgo.

[40] Menezes dos Anjos, E. y Morán Astorga, C. (2016). A personalidade resiliente: uma conceptualizaçao teórica. International Journal of Developmental and Educational Psychology. INFAD Revista de Psicología, Nol-Vol.2, 151-156.

[41] Menger, P. M. (2006). Artistic labor markets: Contingent work, excess supply and occupational risk management. Handbook of the Economics of Art and Culture, 1, 765-811.

[42] Meyer, J.A. y Even, R. (1998). "Marketing and the fine arts. Inventory of a controversial relationship. Journal of Cultural Economics, 22, p. 271-283. [Online] URL http://www.springer.com/economics/journal/10824 
[43] Michael, M. K. (2015). Precarious Practices: Artists, Work and Knowing-in-Practice. Stirling (UK): University of Stirling.

[44] Morán, C. (2005). Relación entre variables de personalidad y estrategias de afrontamiento del estrés laboral. León (Spain): Universidad de León.

[45] Montero Muradas, I. y Oreja Rodríguez, J. R. (2007). El artista y su relación con el mercado del arte. In El comportamiento de la empresa ante entornos dinámicos: $X I X$ Congreso anual y XV Congreso Hispano Francés de $A E D E M$ (p. 71). Asociación Española de Dirección y Economía de la Empresa (AEDEM).

[46] National Coalition for Arts' Preparedness and Emergency Response (2012). A Vision for Emergency Readiness, Response and Recovery in the Arts Sector [Online] URL http://www.giarts.org/sites/default/files/A-Vision-For-Emer gency-Readiness-Response-Recovery-in-the-Arts-Sector.pd $\mathrm{f}$

[47] Neenan, M. (2017). Developing resilience: A cognitive-behavioural approach. New York (USA): Taylor $\&$ Francis.

[48] Reich, J., Zautra, A., y Hall, J. (Eds.). (2010). Handbook of Adult Resilience. New York (USA): The Guildford Press.

[49] Richaud, M. C. (2013). Contributions to the study and promotion of resilience in socially vulnerable children. American Psychologist, 68(8), 751.

[50] Robinson, M. D., \& Montgomery, S. S. (2000). The time allocation and earnings of artists. Industrial Relations: A Journal of Economy and Society, 39(3), 525-534.

[51] Saleebey, D. (2006). Strengths Perspective in Social Work Practice, 4th Edition. Boston (USA): Allyn \& Bacon.
[52] Seligman, M. E. (2014). Florecer: La nueva psicología positiva y la búsqueda del bienestar. Editorial Oceano.

[53] Seligman, M.E.P. (2011). La vida que florece. Una nueva concepción visionaria de la felicidad y el bienestar. Barcelona (Spain): Ediciones B.

[54] Seligman, M.E.P. (2006). Authentic Happiness. [Online] URL

http://www.authentichappiness.sas.upenn.edu/Default.aspx

[55] Seligman, M.E.P. (2002). Positive psychology, positive prevention, and positive therapy. Handbook of positive psychology, 2, 3-12. New York (USA): Oxford University Press.

[56] Snyder, C. R., y Lopez, S. J. (2009). Oxford handbook of positive psychology. New York (USA): Oxford University Press.

[57] Steiner, L., \& Schneider, L. (2013). The happy artist: an empirical application of the work-preference model. Journal of Cultural Economics, 37(2), 225-246.

[58] Throsby, D. (1994). The production and consumption of the arts: A view of cultural economics. Journal of economic literature, 32(1), 1-29.

[59] Throsby, D. (2001). Economics and culture. Cambridge University Press.

[60] Wassall, G. H., \& Alper, N. O. (1992). Toward a Unified Theory of the Determinants of the Earnings of Artists. Cultural economics (pp. 187-200). Springer, Berlin, Heidelberg.

[61] Yapu, M. (et al.) (2006). Pautas metodológicas para investigaciones cualitativas y cuantitativas en ciencias sociales y humanas. La Paz (Bolivia): PIEB. 